\title{
Extensão Universitária: uma experiência com ensino de programação para crianças
}

\author{
Alexandre da Rosa ${ }^{1}$, Camila Nakoneczny ${ }^{1}$, Claisa Lubke', Gabriel Vaz Igarashi', \\ Romualdo Viana Filho ${ }^{1}$, Vinicius Struginski Pereira ${ }^{1}$, Andreia de Jesus ${ }^{2}$, \\ Alexander Robert Kutzke ${ }^{2}$ \\ ${ }^{1}$ Acadêmico do curso superior de Tecnologia em Análise e Desenvolvimento de \\ Sistemas - Setor de Educação Profissional e Tecnológica - Universidade Federal do \\ Paraná (UFPR) - Curitiba - PR - Brazil \\ ${ }^{2}$ Docente do Setor de Educação Profissional e Tecnológica - Universidade Federal do \\ Paraná (UFPR) - Curitiba - PR - Brazil \\ \{alexandrerosa, pierri, claisalubke, gabriel.igarashi, romualdo.viana, \\ struginskipereira, andreia.jesus, alexander\}@ufpr.br
}

\begin{abstract}
This paper presents a university extension project called 'Building Knowledge with Computer and Internet - 1st. edition. The focus is on the activities performed by the 'Thinking with the Computer' working group. This group proposes to teach kids computer programming in order to improve their logical reasoning, help in the troubleshooting practice and motivate them towards school activities that require such skills.
\end{abstract}

Resumo. Este artigo apresenta um projeto de extensão universitária denominado 'Construindo Saberes através do Computador e Internet - $1^{a}$. edição'. O objetivo é destacar as atividades realizadas pelo grupo de trabalho 'Raciocinando com o Computador'. Este grupo propõe ensinar programação de computadores para crianças, a fim de aprimorar o raciocínio lógico delas e, com isso, auxiliar na prática de resolução de problemas e motivá-las para as atividades escolares que exigem esse tipo de habilidade.

\section{Introdução}

O Projeto de Extensão Universitária 'Construindo Saberes através do Computador e Internet $-1^{\text {a }}$. Edição' foi desenvolvido com o intuito de disseminar a Inclusão Sociodigital em um ambiente escolar [Jesus, 2016], por meio de diferentes aspectos: técnico, social, jurídico e pedagógico. Para tanto, foram constituídos 6 grupos de trabalho: Grupo 1: Alfabetização Digital; Grupo 2: O Computador no Processo Ensino-Aprendizagem; Grupo 3: Raciocinando com o Computador; Grupo 4: Internet como Ferramenta de Pesquisa; Grupo 5: Uso Consciente do Computador e Internet; Grupo 6: Aprendendo Inglês no Ambiente Digital. Este projeto é desenvolvido na Universidade Federal do Paraná (UFPR) no setor de Educação Profissional e Tecnológica e envolve acadêmicos de diversos cursos de graduação. As atividades da primeira edição do projeto foram realizadas na Escola Estadual Dom Pedro II, em Curitiba, no período de fevereiro a dezembro de 2016. Este artigo, em especial, aborda o trabalho realizado pelo Grupo 3: Raciocinando com o Computador, cujo objetivo é ensinar programação de computadores para crianças, a fim de aprimorar o raciocínio 
VIII Congresso Brasileiro de Informática na Educação (CBIE 2019)

Anais do XXV Workshop de Informática na Escola (WIE 2019)

lógico delas e, com isso, auxiliar na prática de resolução de problemas e motivá-las para as atividades escolares que exigem esse tipo de habilidade.

A escola estadual dispunha de somente um laboratório de informática com 10 computadores. Devido a isto, foi necessário restringir o número de vagas para a atividade; 20 vagas para o período da manhã e 22 vagas para o período da tarde. Logo, as atividades da oficina foram realizadas em dupla e trios de alunos por computador. Os participantes frequentavam o $6^{\circ}$ Ano do Ensino Fundamental. Além disto, houve a participação de um aluno com deficiência visual, que ficou sob a tutoria dos acadêmicos extensionistas que ministraram a oficina no período manhã.

\section{Referencial Teórico}

A elaboração das tarefas e atividades promovidas pelo projeto de extensão 'Construindo Saberes através do Computador e Internet - $1^{\mathrm{a}}$. Edição' teve como premissa considerar o conceito de Inclusão Sociodigital, que fundamentou a proposta do projeto. Logo, o objetivo desta seção é apresentar esse conceito, a fim de facilitar a compreensão da característica da atividade que será descrita na próxima seção.

Primeiro vamos abordar os diversos elementos que envolvem o conceito de Inclusão Digital, considerando os pilares apresentados por Silva (2003): (1) Tecnologias da Informação e Comunicação (TIC's); (2) renda; (3) educação. Segundo o autor esses três pilares formam um tripé fundamental para que a Inclusão Digital aconteça. As (1) TIC's são o conteúdo a ser transmitido aos beneficiários da inclusão e as ferramentas introduzidas no dia a dia da comunidade, permitindo uma nova gama de oportunidades e interações aos envolvidos, além de sua limitação regional. A (2) renda é a base econômica que dá suporte a este processo. Independente da forma com que o processo seja aplicado, recursos serão necessários para que o ambiente de aplicação seja viável, além de influenciar o cotidiano da comunidade, dando a ela capacidade de tornar a inclusão contínua e não só limitada ao ambiente do projeto de inclusão. Por fim, o último pilar é a (3) educação, que deve atuar como uma parceira do processo de Inclusão Digital. Segundo Silva (2003), o melhor método de aplicar os processos de inclusão é quando o mesmo passa a fazer parte do processo educacional, pois desta forma existe a garantia que o processo de inclusão utilizará de preceitos e metodologias que otimizam o aprendizado dos beneficiados sobre as TIC's.

Além disso, é necessário promover o Letramento Digital que é requisito essencial para uma inclusão efetiva, que vai além do digital e atinja o social. Considerando que letramento é a "Capacidade de ler e de escrever ou de interpretar o que se escreve ["letramento", in Dicionário Priberam da Língua Portuguesa, 20082013]. Contudo, quando a leitura, escrita e interpretação estão intrinsicamente relacionadas com Tecnologias de Informação e Comunicação, o letramento passa a ser mais específico, surgindo o termo Letramento Digital. Conforme Jesus (2006), o Letramento Digital vai além do conhecimento técnico sobre as ferramentas digitais, e é atingido quando o usuário compreende as possibilidades de tais aparatos e se torna capaz de adaptá-los a suas demandas. 
VIII Congresso Brasileiro de Informática na Educação (CBIE 2019)

Anais do XXV Workshop de Informática na Escola (WIE 2019)

\section{Metodologia do Trabalho}

Tendo em vista o ensino de programação para crianças, buscou-se uma metodologia que abordasse o tema de forma simples, leve e divertida, senão esta atividade teria grandes chances de não atingir seu objetivo. Logo, um grande desafio para acadêmicos extensionistas do curso superior de Tecnologia em Análise e Desenvolvimento de Sistemas é a elaboração de material didático sobre esse tema para crianças entre 11 e 12 anos. A carga horária total da atividade é de 18 horas, sendo distribuída em 6 encontros semanais de 3 horas cada um. É importante colocar que tanto a carga horária como a distribuição das horas foram definidas em parceria com a equipe pedagógica da escola, a fim de atender o contexto daquela comunidade. E, com base nisto, foram definidas as seguintes etapas para a metodologia da atividade:

Etapa 1: Iniciou-se com a introdução de conceitos sobre o funcionamento do computador. Tal assunto foi introduzido através de uma atividade sobre números binários, baseada no livro 'Ciência da Computação Desplugada' (BELL et. al, 2011). A atividade consistia em utilizar folhas A4 com conjuntos de círculos impressos para demonstrar o funcionamento dos bits e sua fundamentação em base de 2. Com isto, alguns alunos da turma foram à frente da sala e seguraram as folhas, enquanto os demais davam instruções para a montagem de números predeterminados em binário. Tais folhas foram desenvolvidas em alto relevo para inclusão do aluno com deficiência visual

Etapa 2: Apresentação do conceito de algoritmos. Para tanto, foram utilizadas descrições de atividades do cotidiano das crianças. Os alunos liam seus algoritmos em voz alta e comparações eram realizadas de forma a comprovar que haviam várias soluções diferentes para o mesmo problema.

Etapa 3: Aplicação do software LightBot [Gouws, et. al, 2013] para fixar o conceito de comandos sequenciais de um algoritmo e introduzir blocos de comandos predefinidos, característicos das linguagens de programação (Figura 1(a)). As atividades foram desenvolvidas com o uso dos exercícios do bloco 'básico' da ferramenta LightBot. Além disso, a atividade foi adaptada pelos extensionistas com o desenvolvimento de uma versão física do LightBot (Figura 1 (b)). Desta forma foi possível atender as necessidades do aluno com deficiência visual.

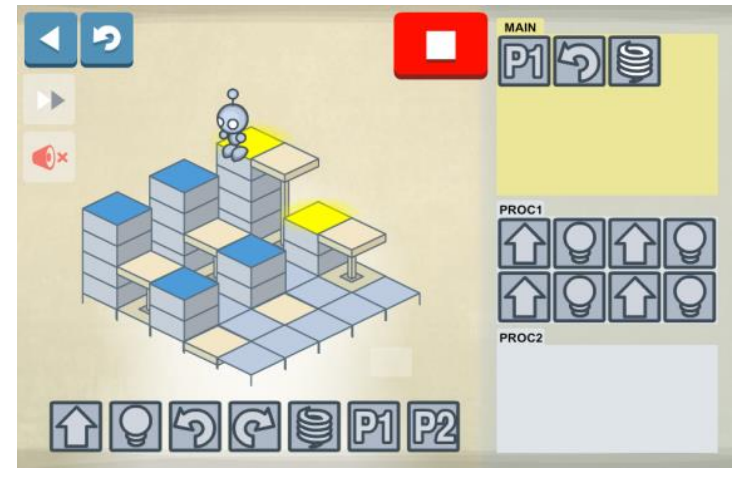

(a) Interface digital da Ferramenta LightBot (2019).

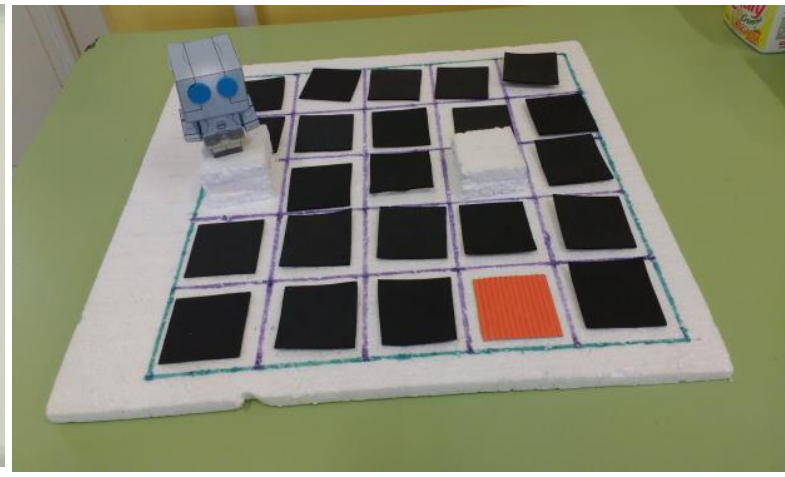

(b) Interface física da ferramenta LightBot.

Figura 1. Interfaces da ferramenta LightBot. 
VIII Congresso Brasileiro de Informática na Educação (CBIE 2019)

Anais do XXV Workshop de Informática na Escola (WIE 2019)

Etapa 4: Utilização do software Scratch [Maloney et al. 2010] para aplicar efetivamente os conhecimentos adquiridos até a Etapa 3 da oficina. O mesmo foi adotado devido ao fato de permitir aprofundar ludicamente os conteúdos já apresentados. Nesta etapa, o primeiro passo foi ensinar para as crianças a lógica da ferramenta e como implementar os algoritmos. As atividades foram intercaladas entre: (1) ensinar como aplicar um conhecimento lógico no Scratch, como por exemplo, sentenças condicionais; (2) aplicar este conhecimento programando a solução para um problema simples. Devido ao fato de o Scratch também ser uma ferramenta visual, foi necessário adaptar a atividade para atender as necessidades do aluno com deficiência visual. Então, foi aplicado o ambiente de desenvolvimento VisualAlg, por permitir programação baseada em linguagem natural em português. $O$ aluno recebeu acompanhamento individual durante as atividades. Observação: o conteúdo escrito de todas as atividades foi adaptado em Braille.

Etapa 5: nesta etapa, as crianças foram desafiadas a desenvolver seus próprios programas. Assim, nos dois últimos encontros, as crianças desenvolveram jogos digitais de forma livre e em equipe, sendo que os extensionistas estavam em sala somente para esclarecer dúvidas e auxiliá-las em suas ideias.

\section{Análise da Prática}

Além dos resultados óbvios que foram obtidos com o desenvolvimento dos jogos digitais, também foram coletados dados por meio de questionários realizados com as crianças antes e depois da atividade. O resultado apresentado abaixo é referente as análises feitas pelos acadêmicos do curso superior de Tecnologia em Gestão da Qualidade do Setor de Educação Profissional e Tecnológica da UFPR.

Quando confrontados com a afirmação "Sei descrever passo a passo a solução de um problema" os alunos apresentam um aumento de 33\% (antes da oficina) para $77 \%$ (depois da oficina) na turma da manhã e de 36\% (antes da oficina) para $72 \%$ (depois da oficina) na turma da tarde. Isto demonstra uma clara melhora na capacidade das crianças resolverem problemas estruturalmente.

Já, na turma da manhã, é possível verificar que a distribuição com relação a concordância da afirmativa "Tenho persistência na solução computacional de um problema" ficou entre os graus 3, 4 e 5 (escala gradativa de 1 a 5. Em que 1- não tenho nenhuma persistência; 5- tenho total persistência), antes da realização da oficina. E após a realização da oficina houve uma melhora de $12 \%$ dos alunos dessa turma, os quais se consideraram grau 5, o que quer dizer que são persistentes na solução computacional de um problema. Com relação a mesma afirmativa antes da realização da oficina para a turma da tarde, não obtivemos respostas com graus 4 e 5 de concordância, indicando um desconhecimento muito grande quanto a esse quesito. Após a oficina, 66\% dos alunos dessa turma passaram a concordar com essa afirmação do questionário (graus 4 e 5), demonstrando possuir conhecimento suficiente sobre o tema proposto.

É possível observar que o grau de eficiência do projeto atingiu bons números, apesar das diversas dificuldades enfrentadas no decorrer das atividades. Sendo a dificuldade mais relevante a falta de infraestrutura para comportar o número de alunos 
VIII Congresso Brasileiro de Informática na Educação (CBIE 2019)

Anais do XXV Workshop de Informática na Escola (WIE 2019)

matriculados na oficina, além da rede de Internet possuir uma velocidade baixíssima em vista das atividades que estavam sendo realizadas em sala. Porém, a atividade atingiu seu objetivo, principalmente, porque promoveu o letramento digital das crianças. Isto porque elas aprenderam muito além de comandos de programação, desenvolveram a habilidade de resolver problemas de forma estruturada. E este aprendizado elas podem aplicar nas atividades escolares e nas atividades do seu dia a dia.

\section{Considerações Finais}

Tanto os acadêmicos extensionistas, quanto as crianças participantes ganharam novos conhecimentos durante o projeto. As crianças que demonstraram interesse pelos temas estudados agora possuem capacidade de aplicar esse conhecimento em seu dia a dia. Já os extensionistas da área da tecnologia entraram em contato com atividades relacionadas a educação, uma experiência única no âmbito do curso a que pertencem.

Conclui-se que o projeto foi bem-sucedido. Dados colhidos e o retorno do corpo docente da escola demonstraram que o projeto trouxe diversas melhorias e avanços. Tal feedback garantiu a segunda edição do projeto, que agora com um embasamento melhor sobre as características humanas e estruturais da escola, permite a atualização das atividades e a efetivação do processo de inclusão sociodigital neste ambiente escolar.

\section{Referências}

Bell, T., Witten, I. H., Fellow, M. (2011) "Computer Science Unplugged: Ensinando Ciência da Computação sem o uso do computador". Tradução coordenada por Luciano Porto Barreto.

Gouws, L. A., Bradshaw, K., and Wentworth, P. (2013). Computational thinking in educational activities: an evaluation of the educational game light-bot. In Proceedings of the 18th ACM conference on Innovation and technology in computer science education, pages 10-15. ACM.

Jesus, A. et. al. (2016) Fundamentação e Proposta de um Projeto de Extensão: Construindo Saberes Através do Computador e internet. In: 7o. Congresso Brasileiro de Extensão Universitária, 2016, Ouro Preto. 7o. Congresso Brasileiro de Extensão Universitária.

Jesus, A. (2006) "Experiências de um Projeto de Inclusão Digital: A Prática Pedagógica de Acadêmicos de Licenciatura em Computação", In: Anais do XXVI Congresso da Sociedade Brasileira de Computação, Campo Grande, MS.

Maloney, J., Resnick, M., Rusk, N., Silverman, B., and Eastmond, E. (2010). "The scratch programming language and environment". ACM Transactions on Computing Education (TOCE), 10(4):16.

Silva, A. M. (2003) "Os três pilares da Inclusão Digital”. Revista Espaço Acadêmico Ano III - no. 24 - ISSN 1519.6186. 